\title{
OUTCOME OF STUDY OF IMMEDIATE HIP SPICA APPLICATION IN FEMORAL DIAPHYSEAL FRACTURES IN CHILDREN
}

\author{
Tapan Kumar Das ${ }^{1}$, Anupam Debnath ${ }^{2}$, Bhupes Sil ${ }^{3}$
}

${ }^{1}$ Associate Professor, Department of Orthopaedics, AGMC, Agartala, Tripura.

${ }^{2}$ Registrar, Department of Orthopaedics, AGMC, Agartala, Tripura.

${ }^{3}$ Assistant Professor, Department of Orthopaedics, AGMC, Agartala, Tripura.

\begin{abstract}
BACKGROUND

Femoral shaft fractures in the paediatric patients have traditionally been treated non-operatively with either early spica cast or a period of traction followed by application of hip spica cast until the time of fracture union. Surgical treatment invites complications. Immediate hip spica casting indeed leads to significant reductions in weight-bearing delay, hospitalisation duration, complications and costs, while having similar clinical results as traction.
\end{abstract}

Aims- Aim of the study was to assess the final outcome related to the study.

\section{MATERIALS AND METHODS}

We conducted a prospective study over a period of two years on 45 patients with closed shaft femur fractures below 10 years of age, treated by immediate hip spica casting. Under fluoroscopy, fracture was reduced on the same day of presentation to hospital. Patients were discharged after 24 hours of observation.

\section{RESULTS}

The average hospital stay was 1.5 days. The average duration of followup was 6.4 months. The average shortening of the fractured limb at the time of fracture union was $11 \mathrm{~mm}$. The average shortening of limb at the last followup was $7 \mathrm{~mm}$. All fractures united in an acceptable position except one.

\section{CONCLUSION}

Immediate hip spica casting be considered as the gold standard for closed femoral shaft fracture in children $<10$ years.

\section{KEYWORDS}

Hip Spica, Femoral, Immediate, Diaphyseal.

HOW TO CITE THIS ARTICLE: Das TK, Debnath A, Sil B. Outcome of study of immediate hip spica application in femoral diaphyseal fractures in children. J. Evolution Med. Dent. Sci. 2017;6 (42):3344-3346, DOI: 10.14260/Jemds/2017/724

\section{BACKGROUND \\ Aims and Objectives}

Femoral shaft fractures represent approximately $1.6 \%$ of all bony injuries in children. ${ }^{1}$ It is among the most common causes of hospitalisation for paediatric orthopaedic injuries. ${ }^{2}$ Bilateral femoral shaft fractures are extremely rare. They are usually treated by initial traction for 3 to 4 weeks followed by an additional period of immobilisation in hip spica cast. ${ }^{3}$ Such treatment involves prolonged hospital stay, increase cost and occupancy of hospital beds. Surgical treatment has its own complications. External fixators are associated with increased chances of pin tract infection and refracture. Plate osteosynthesis need extensive soft tissue stripping and repeat surgery for removal of implant. Intramedullary rods increase chances of avascular necrosis of femoral head and damage to physis. ${ }^{4}$ Immediate hip spica casting indeed leads to significant reductions in hospital stay, complications and cost of treatment.

Financial or Other, Competing Interest: None.

Submission 10-02-2017, Peer Review 12-05-2017,

Acceptance 18-05-2017, Published 25-05-2017.

Corresponding Author:

Dr. Anupam Debnath,

Vill-Kashipur, Mission Road,

P.O-Reshambagan,

Agartala-799008

Tripura.

E-mail: anupamdebnath54@gmail.com

DOI: $10.14260 /$ jemds $/ 2017 / 724$

Aim of the study was to assess the final outcome related to the study. Objectives were to study the duration and quality of bony union, complications of early hip spica and to decrease the cost of hospital stay.

\section{MATERIALS AND METHODS}

- 45 patients in the age group of 1 - 10 years presented with unilateral femoral shaft fractures, who attended the Department of Orthopaedics, Agartala Govt. Medical College and Hospital, were studied from July 2013 to June 2015 (2 years).

- Exclusion Criteria- Age $<1$ year and $>10$ years, bilateral femoral shaft fracture, pathological fracture, open fractures, multiple injuries, ipsilateral tibial fracture and past history of fracture in the same lower limb.

- Under fluoroscopy, fracture was reduced on the same day of presentation to hospital. Hip was flexed between $60^{\circ}$ to $90^{\circ}$ for proximal third fracture, $45^{\circ}$ to $60^{\circ}$ for mid third fracture and $30^{\circ}$ to $45^{\circ}$ for distal third fracture. Knee was flexed $60^{\circ}$ in all cases. Abduction was $25^{\circ}$ to $30^{\circ}$ with neutral rotation. No attempt was made to obtain an end to end reduction. We tried to avoid more than $15 \mathrm{~mm}$ of shortening. General anaesthesia was applied in 30 cases. Patients were discharged after 24 hours of observation. Xrays of both femurs were then taken to measure shortening and angulation. The patients were reviewed 
weekly for first 3 weeks, then monthly. X-rays were done on each visit to check the shortening and angulation. After 6 weeks, plaster was removed and union was judged clinically and radiologically. Final outcome was assessed based on Flynn's Grading.

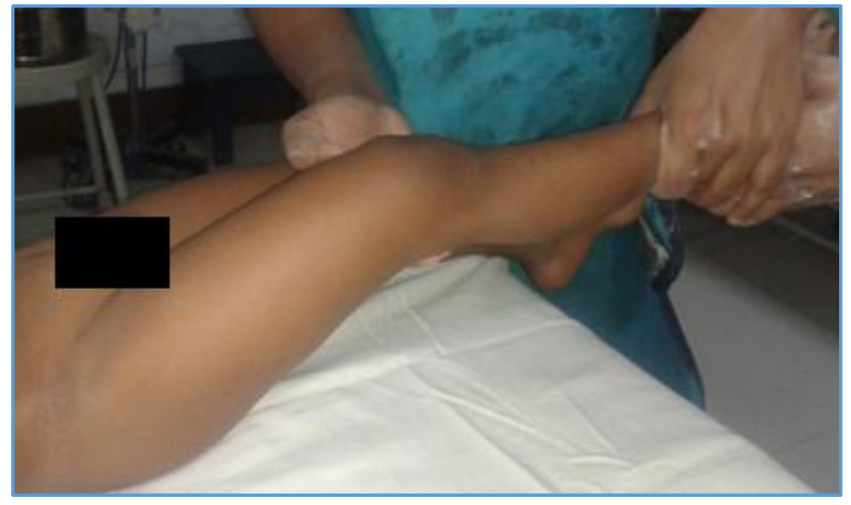

Method of Reduction

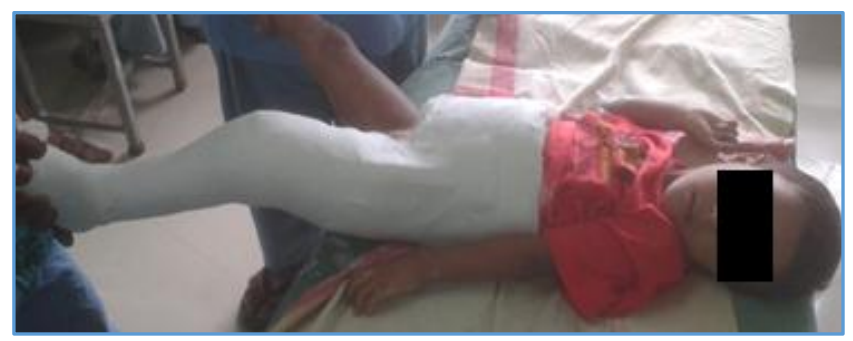

Application of Hip Spica

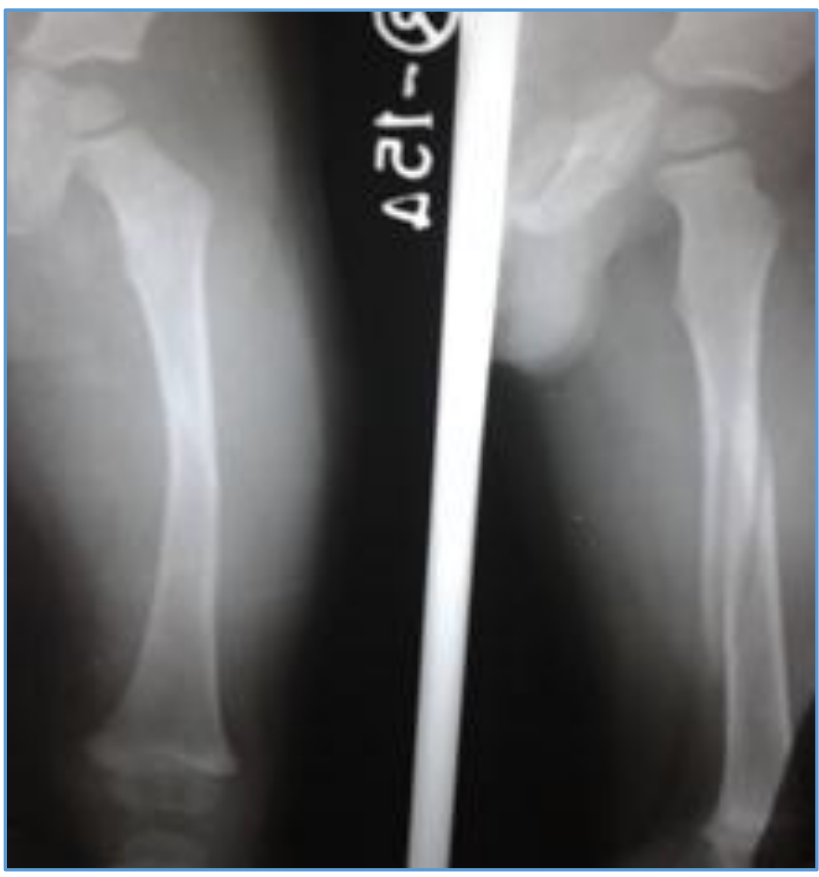

Pre-Reduction X-Ray

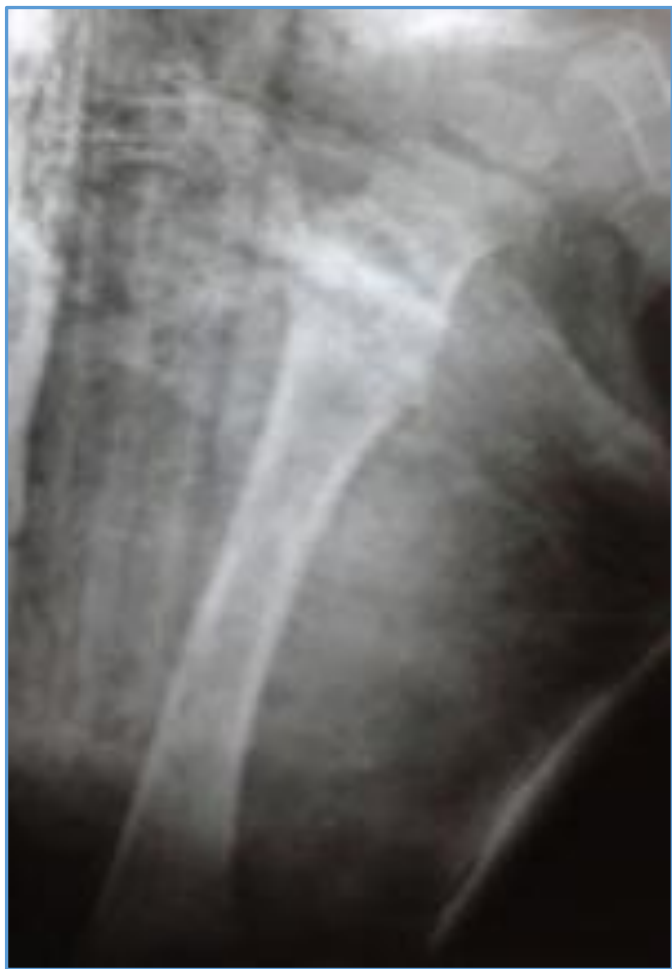

Post Reduction X-Ray

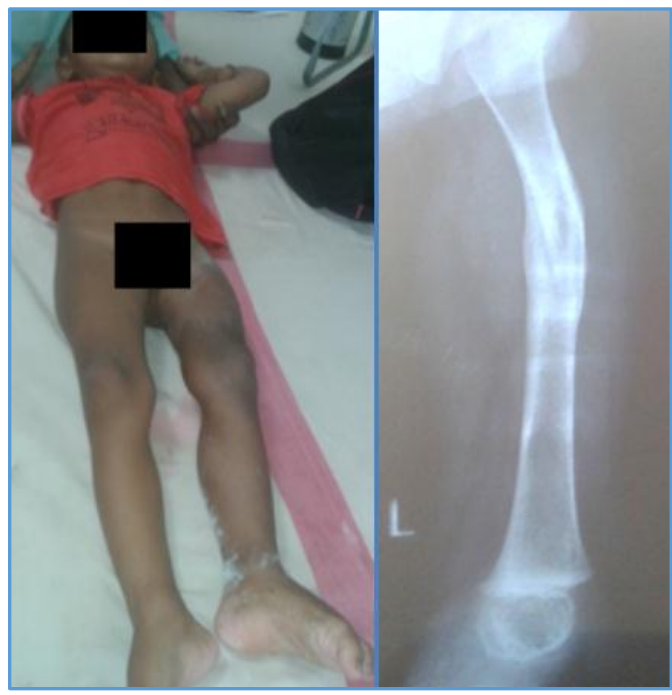

Clinical and Radiological Picture at 8 Weeks Followup

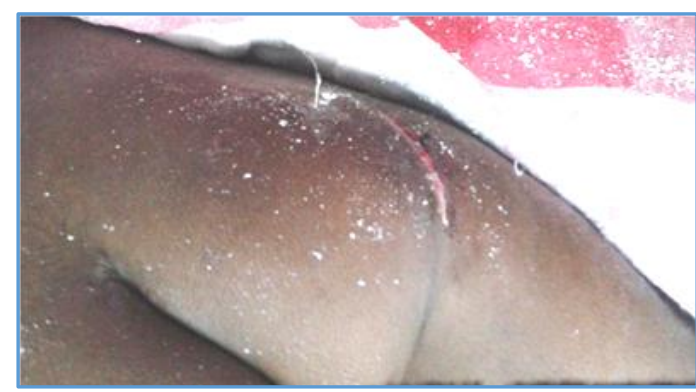

Superficial Plaster Sore over Gluteal Region (A Complication of Spica Cast) 


\section{RESULTS}

50 patients were admitted during the study; 5 patients were lost during followup. Age ranged from 1 year 1 month to 9 years 2 months (average 4 years 4 months). There were 30 male and 15 female patients (male: female= 2:1); $30(66 \%)$ fractures were right sided; $23(50 \%)$ fractures were mid shaft, $13(30 \%)$ were proximal shaft and $9(20 \%)$ were distal shaft fractures.

30 fractures were due to fall and 15 were due to road traffic accident. The average duration of hospital stay was 1.5 days ranging from 1 day to 4 days. The duration of immobilisation in cast ranged from $4-6$ weeks. The average followup was 6.2 months ranging from 4 months to 9 months. Average time of bony union was 50 days ranging from 42 to 60 days. The average shortening was $11 \mathrm{~mm}$ during plaster removal and $7 \mathrm{~mm}$ during final followup (6 months). Limb overgrowth was seen in 12 (26\%) cases. Average angulation in coronal plane was $8^{\circ}$ and in sagittal plane was $10^{\circ}$ at plaster removal; 1 patient developed $25^{\circ}$ angulation in sagittal plane; 1 patient had plaster sore over gluteal area. In 6 cases, hip spica was broken. There was some increase in angulation in first 3 weeks. At the time of union all patients had angulation, which were within acceptable range. Range of movement of hip, knees and ankles were within normal limits during final followup.

\begin{tabular}{|llcc|}
\hline \multicolumn{4}{|c|}{ Flynn's Grading (For assessment of final outcome) } \\
- Limb Length & $<1 \mathrm{~cm}$ & $1-2 \mathrm{~cm}$ & $>2 \mathrm{~cm}$ \\
Discrepency & $18 / 45$ & $27 / 45$ & $0 / 15$ \\
- Misalignment & $<\mathbf{5}^{\mathbf{0}}$ & $\mathbf{5}^{0}-\mathbf{1 0}^{\mathbf{0}}$ & $>\mathbf{1 0}^{\mathbf{0}}$ \\
& $12 / 45$ & $21 / 45$ & $12 / 45$ \\
- Complications & None & Minor \& & Major \& \\
& & resolved & lasting \\
& $36 / 45$ & $9 / 45$ & $0 / 45$ \\
- Overall Results & $24 / 45$ & $18 / 45$ & $3 / 45$ \\
\hline
\end{tabular}

\section{DISCUSSION}

The main concern in the treatment of femoral shaft fracture in children is the problem of limb shortening and deformity. In adults, any shortening would be permanent, but the situation in children is different. Perfect anatomical reduction is not essential for perfect function. The post-traumatic overgrowth phenomenon following fracture has allowed acceptance of shortening up to $1.5 \mathrm{~cm}$ at the time of fracture union. Some overriding is usually desirable at the time of fracture healing. Remodelling is also expected to correct moderate amount of angulation. We have noticed a considerable amount of overgrowth and correction of angulation in most patients. Maximal overgrowth usually occurs between 3 to 6 months after trauma. The problem of early spica application in older children is the tendency of the fracture to override and angulate. This is due to the size of the patients and the tendency in older children to ambulate early without supervision. Remodelling and overgrowth in patient above 10 years of age is generally much less.
Male patients predominated in our study (male: female $=$

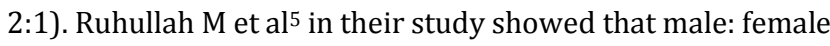
ratio was 2.5:1. Mean age of injury was 4 years 4 months comparable with Ruhullah $\mathrm{M}$ et $\mathrm{al}, 5$ where it was 6.4 years. Average duration of hospital stay was 1.5 days in our study. D'Ollonne $\mathrm{T}$ et $\mathrm{al}^{6}$ found that mean hospitalisation was 18.8 days in skin traction group and 2.8 days in early hip spica group. The duration of cast immobilisation ranged from $4-6$ weeks and average time of union was 50 days. D'Ollonne T et $\mathrm{al}^{6}$ in their study showed that cast immobilisation duration was 76.8 days in skin traction group and 61.5 days in early hip spica group. Angulation was within acceptable range in all cases except in 1 case, where $25^{\circ}$ of angulation was in sagittal plane. Wedging of spica cast done and in long-term follow-up angulation was gradually corrected. Although, some angular deformity occurs after femoral shaft fractures in children, it usually remodels with growth. Angulation of more than 15 degrees in the coronal plane and 20 degrees in the sagittal plane is unacceptable. ${ }^{7}$ One patient had plaster sore over gluteal area, which recovered with dressing and antibiotics. Six children had broken and loosened hip spica on $2^{\text {nd }}$ week and needed reapplication of spica.

\section{CONCLUSION}

Isolated femoral shaft fractures in children aged $<10$ years should be treated non-operatively. Immediate hip spica casting leads to significant reductions in weight-bearing delay, hospitalisation duration, complications and costs. The application of the hip spica must be done carefully and the followup must be strict. Considering these results, we recommend that immediate hip spica casting be considered as the gold standard for closed femoral shaft fracture in children $<10$ years.

\section{REFERENCES}

[1] Bucholz RW, Heckman JD, Brown CC. Rockwood and greens fractures in childrens. Chapter 52. $6^{\text {th }}$ edn. Lippincott Williams and Wilkins 2006: p. 893.

[2] Flynn JM, Schwend RM. Management of pediatric femoral shaft fractures. J Am Acad Orthop Surg 2004;12(5):347-59.

[3] Jamaludin M. Femoral shaft fracture in children treated by early hip spica cast: early result of a prospective study. Med J Malaysia 1995;50(1):72-5.

[4] Egol AK, Koval KJ, Zuckerman JD. Chapter 37. Hand book of fractures. $4^{\text {th }}$ edn. Lippincott Willims and Wilkins 2010; p. 581.

[5] Ruhullah M, Singh HR, Shah S, et al. Hip spica versus Rush pins for management of femoral diaphyseal fractures in children. Indian J Orthop 2014;48(5): 488-94.

[6] d'Ollonne T, Rubio A, Leroux J, et al. Early reduction versus skin traction in the orthopaedic treatment of femoral shaft fractures in children under 6 years old. J Child Orthop 2009;3(3):209-15.

[7] Staheli LT, Sheridan GW. Early spica cast management of femoral shaft fractures in young children. A technique utilizing bilateral fixed skin traction. Clin Orthop Relat Res 1977;126:162-6. 